\title{
La presencia de Dios en el mundo según Atanasio de Alejandría
}

\author{
Xavier Morales \\ Facultad de Teología \\ Pontificia universidad Católica de Chile
}

Antes de empezar mi lección inaugural del año académico 2018, quisiera expresar mi agradecimiento por la acogida tan cordial que he recibido en cuanto nuevo profesor de patrología en esta Facultad. El calor que encuentro aquí, saliendo del invierno europeo, no es sólo cuestión de temperatura del aire. De hecho, descubro que vivir con los pies sobre la cabeza eleva la temperatura de los corazones.

Cuando me pregunté cuál podría ser el tema adecuado de una lección, en el contexto solemne y festivo de una inauguración de curso académico, me pareció importante demostrar que la erudición histórica y la confrontación con los textos mismos, propias de la disciplina patrística, podían desembocar en resultados de naturaleza verdaderamente teológica. Este proyecto parte de una concepción de la patrología que expondré en una primera sección. El resto de la lección formará una puesta en práctica de este proyecto, aplicado a un determinado tema y un determinado texto patrístico. El conjunto representará una suerte de declaración inaugural de propósito de parte de un profesor aún desconocido.

\section{INTRODUCCIÓN: EL CARÁCTER INAUGURAL DE LA PATROLOGÍA}

En el ambiente del Medio Oriente antiguo, los hijos de Israel demostraban la verdad de su Dios por medio de una prueba de poderes: el poder del Señor de Israel era superior al de los supuestos dioses de sus vecinos ${ }^{1}$.

W. Pannenberg, Teología sistemática, I, tr. esp. (Madrid 1992), caracteriza las religiones politeístas como "veneración de poderes que se le muestran como eficaces y reales a la experiencia humana" (p. 171 [175]), y habla de la "confrontación” de cada "figura divina" "con otros dioses y otras pretensiones de verdad en competencia con ella” (p. 158 [163]). 
En el ambiente del Mediterráneo helenístico, los cristianos también denunciaron la debilidad y la vanidad de los supuestos dioses griegos o latinos, mientras anunciaban al "Dios vivo y verdadero" $(1$ Ts 1,9$)$. Pero muy pronto se enteraron de una posible alianza con una corriente interna a la cultura helenística, que también criticaba las divinidades tradicionales y apuntaba hacia un principio único del universo: me refiero a la tradición filosófica.

El encuentro del cristianismo con la tradición filosófica no es sólo una cuestión de estrategia misionera. El hecho de que el misterio de Dios pueda decirse en el discurso racional, significa que este misterio puede ser comunicado universalmente a todos los hombres en cuanto seres racionales.

Y tal es la tarea esencial de la teología, si bien la entiendo. Está claro que, como lo dijo nuestro decano hace pocos días, en su acogida a los novatos, esta tarea es una tarea secundaria en comparación con la tarea kerigmática del anuncio de la salvación en Jesucristo. Pero la tarea teológica condiciona la posibilidad de que este anuncio pueda llegar a todos los hombres y no sólo a los que comparten la tradición de Abrahán y Moisés.

Los judíos también se enfrentaron a esta tarea. Vemos algunos de los resultados en los libros "sapienciales" de la Biblia, unos de los cuales fueron escritos directamente en griego, el idioma de la tradición filosófica. Y las obras del judío Filón de Alejandría, casi contemporáneo de Jesús de Nazaret, pueden pretender al título de fuente y modelo de la teología cristiana.

La teología es el encuentro entre el anuncio del Dios de Jesucristo y el logos filosófico. Ahora bien, este encuentro tuvo lugar de manera inaugural en la época patrística. Por lo tanto, la elección de un tema patrístico para abrir este nuevo curso de la Facultad de Teología no es una pura casualidad. Algunos dirán que, naturalmente, la lección inaugural me fue pedida a mí porque yo mismo inauguraba mi docencia en esta facultad. Sea lo que fuere, estoy convencido del carácter esencialmente inaugural, o introductorio, de la patrología. De este modo, no puede reducirse a una subdivisión de la historia de la Iglesia o de las doctrinas cristianas, de interés puramente arqueológico. Con la patrología, se trata de introducir a la tarea principal de la teología, el discurso racional sobre el Dios de Jesucristo. Lo que la teología fundamental hace, desde la especulación filosófica, lo hace la patrología desde la filología y la historia: proporciona los fundamentos del edificio teológico. 
Hoy quisiera aproximarme a un tema tópico, tanto en la tradición filosófica como en la tradición bíblica, y que sigue siendo un tema existencial para nosotros, puesto que nos toca literalmente a todos: la relación entre Dios y el mundo.

En la época patrística, hay una ciudad que representa por antonomasia el diálogo entre mensaje bíblico y racionalidad filosófica: me refiero a Alejandría. Atanasio, obispo de esta ciudad en el siglo IV, escribió un doble tratado apologético Contra los paganos [CG] y sobre la encarnación del Verbo [DI], donde se opera una integración crítica del concepto filosófico de la inmanencia del principio divino en el mundo, en el marco del acontecimiento histórico de la venida del Logos divino en nuestra carne. Leamos juntos algunas páginas de esta obra famosísima.

\section{Contra los Paganos: trascendencia del Verbo de Dios}

Atanasio dedica los últimos capítulos del primer tratado, Contra los paganos, a la descripción de la armonía y la unidad del universo, que postulan un creador o "demiurgo", no solamente único, sino también racional, un creador dotado de logos. Este creador, afirma el alejandrino,

¿Quién es, sino el Padre de Cristo, santísimo y más allá de todo ser advenido al ser, el que, en cuanto excelente piloto, pilota salvíficamente las cosas <que están> por todas partes, por su propia sabiduría y su propio Logos, nuestro señor y salvador Cristo, y las ordena y las hace como le parece que estén bien? ${ }^{2}$

La analogía del piloto que dirige su barco es una analogía tradicional, tan difusa en tiempo de Atanasio, que no se refiere a una determinada doctrina filosófica. Basta recordar que Platón la usaba en el libro VI de la República para hablar de la tarea de los filósofos en el gobierno de las ciudades $^{3}$, y en el Politico, para el gobierno del mundo por el dios creador ${ }^{4}$, tal como el autor del pseudo-aristotélico Acerca del Mundo, escribiendo en

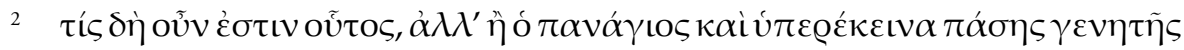

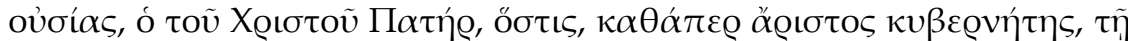

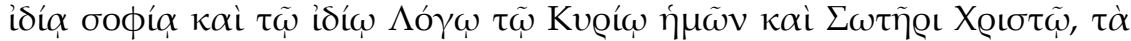

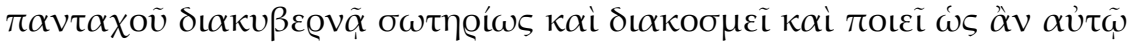



3 Platón, República, VI, 488a7-489c7.

4 Platón, Político, 272e3-6. 
el primer siglo antes de Cristo: "Lo que <hace> en su barco el piloto [...] lo $<$ hace $>$ Dios en el mundo"'s.

La analogía apunta evidentemente hacia la acción del piloto, y no hacia su presencia en el barco. Por lo tanto, como lo reconocieron Aristóteles ${ }^{6}$, Alejandro de Afrodisia ${ }^{7}$ o Plotino $^{8}$, la analogía, que, en este caso, aplican al alma, dirigente del cuerpo ${ }^{9}$, es deficiente, puesto que conlleva la idea de que el alma "esté en algo", o sea, esté ontológicamente determinada por un "dónde".

De hecho, el autor del tratado Acerca del mundo insiste sobre la trascendencia de la divinidad que produjo el mundo. Escribe:

$<$ El dios> no está en el medio, aquí donde está la tierra, este lugar túrbido, pero, <como es > puro, queda arriba, en un lugar puro, que llamamos cielo... ${ }^{10}$.

El dios demiurgo no produce sus efectos por ningún contacto con el mundo sino a distancia, porque una larga cadena de causas intermedias obedece a su potencia infinita. La analogía del piloto sólo es una de muchas analogías empleadas para describir esta relación de potencia

5 Pseudo-Aristóteles (siglo I a. J.C), Acerca del mundo, VI, 400b6...9 (en Aristotle. On the Cosmos, ed. D.J. Furley [The Loeb Classical Library 400, Londres 1978] 402):

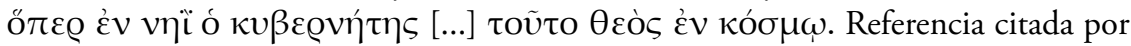
E.P. Meijering, Athanasius: Contra Gentes. Introduction, translation and commentary (Leiden 1984) 129. Alcinoos, Didaskalikos, xxx, H 184, 1. 6-9, ed. por J. Whittaker (Paris 2002) 61, aplica la analogía a la prudencia, y se sirve también de la analogía del general y de su ejército.

6 Aristóteles, Acerca del alma, II, i, 413a8-9: “Todavía no queda claro si el alma es la realización del cuerpo como el navegante lo es del barco."

7 Alejandro de Afrodisia, Acerca del alma, 15.

8 Plotino, Tratado 27 (Enn. IV, 3), 21.

9 En "L'immortalité de l'âme et de l'intellect d'après Aristote", Revue philosophique de Louvain 51 (1953) 444-472, A. Mansion demuestra que la comparación de la relación entre alma y cuerpo a la relación entre piloto y nave no viene de Platón y fue siempre atribuida a Aristóteles por los comentaristas antiguos, que la interpretan en el contexto de la cuestión de la existencia separable del alma; el responsable de la atribución tradicional a Platón sería Tomás de Aquino (p. 456-465).

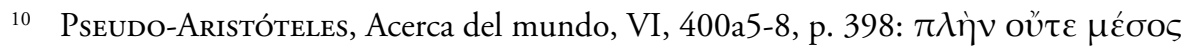

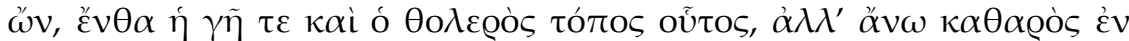

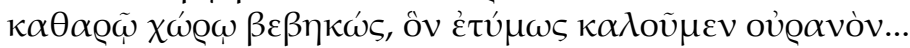


y obediencia. Citemos las imágenes del Gran Rey de Persia, del jefe de coro, del general de ejército, o del alma en el cuerpo. Todas apuntan hacia la relación de potencia y obediencia, sin respecto a la cercanía o distancia entre los términos.

Atanasio también insiste en la trascendencia ontológica del Dios "demiurgo", cuando le aplica una famosísima expresión platónica: "más allá del ser" ${ }^{11}$.

Está claro que, bajo la pluma de Atanasio, esta expresión no tiene ninguna connotación apofática. Atanasio no está declarando que Dios trasciende el ser mismo, a la manera del Uno de Plotino, del que no se puede decir ni que "es" ${ }^{2}$. Tal declaración, en Plotino, lleva a hacer una distinción entre este "Uno" y el principio creador del universo, el Intelecto. Esta distinción ya se encuentra en Numenio, donde el dios demiurgo, cual un piloto, dirige el barco del mundo material, la mirada dirigida hacia el primer dios trascendente e inmóvil ${ }^{13}$. Atanasio, al identificar al creador con el Dios que está más allá del ser, rechaza esta distinción ${ }^{14}$.

Este rechazo es deliberado. Correlativamente, en el pasaje del tratado Contra los paganos que estamos leyendo, Atanasio atribuye preferencialmente el título de "demiurgo" al Padre, y no al Verbo de Dios ${ }^{15}$, aunque el Padre lleve a cabo esta operación de creación y ordenación del mundo mediante su Verbo. Atribuir el título de "demiurgo" al Verbo llevaría a distinguirle de un Dios trascendente y, por lo tanto, a considerarle como inmanente al mundo.

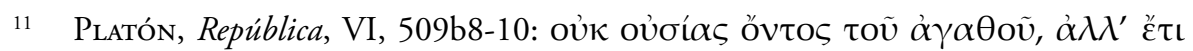


do por Eusebio de Cesarea en su Preparación evangélica, XI, 21, 6, 1. 4-5 (Sources Chrétiennes 292) 154.

12 Ver por ejemplo Plotino, Tratado 7 (Enn. V, 4), 1; Tratado 9 (VI, 9), 2.

13 Numenio, Sobre el bien, fr. 18, transmitido por Eusebio de Cesarea, Preparación evangélica, XI, 18, 24.

14 Como dice acertadamente E.P. Meijering, Athanasius: Contra Gentes..., 16: "Athanasius does not betray any profound knowledge of Neo-Platonism".

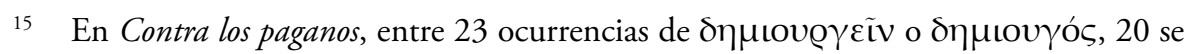
refieren a Dios, y sólo 3 al Verbo $(29,5 ; 46,7 ; 47,1)$. Atanasio abandona su prudencia en Sobre la encarnación, con 10 ocurrencias para Dios $(5$ mencionando explícitamente al Padre) y 6 para el Verbo. Ver S. ZaŃartu, "El logos en el De incarnatione Verbi de Atanasio. Una primera aproximación”, Teología y Vida 48 (2007) 261-301, aquí 270-271. 
Ahora bien, la idea de que el principio de ordenación del mundo, su logos o verbo, fuera inmanente al mundo, es típica de la tradición estoica16. Esta idea también la rechaza Atanasio, cuando distingue tres géneros de $\log o i^{17}$.

El primer género de logoi es el logos de las palabras pronunciadas por los hombres, compuestas de sílabas, y tan evanescentes como el aire. El logos creador, por supuesto, es diferente de este logos. Pero tampoco se identifica con

el logos que está naturalmente vinculado y unido a cada $<\operatorname{cosa}>$ advenida al ser, el que algunos suelen llamar "seminal" - <este logos> no está animado, no razona ni piensa, pero actúa solamente gracias a un arte extrínseco, según la ciencia del que lo usa ${ }^{18}$.

El logos con el que Dios crea y ordena el mundo, el "Verbo de Dios", no solamente, al contrario de estos dos primeros logoi, tiene existencia por sí mismo, sino que, tal como el Dios demiurgo, trasciende ontológicamente el mundo: "Es otro que las $<\operatorname{cosas}>$ advenidas al ser y que toda la creación” ${ }^{\prime 1}$.

16 Ver Diógenes Laercio, Vidas y opiniones de los filósofos más ilustres, VII, 134, l. 10841085, ed. T. Dorandi (Cambridge Classical Texts and Commentaries 50, Cambridge 2013) 552, también en Stoicorum veterum fragmenta, vol. II, ed. por J. von Arnim (Stuttgart 1903, n. 300) p. 111, 1. 9-10, que habla de dos principios del universeo: "el ser sin calidades, o sea la materia" y "el Logos <que está > en ella, o sea el dios"; y Alejandro de Afrodisia, Acerca de la mezcla, ed. Bruns. p. 225, 1. 1-2, en Stoicorum veterum fragmenta, vol. II, n. 310, p. 112, 1. 29-31: "el dios, dicen, está mezclado con la materia, extendiéndose por toda ella, dándole forma, figura y convirtiéndola así en mundo". Ver sobre todo la teoría de los logoi spermatikoi, expuesta, por ejemplo, en Diógenes Laercio, Vidas y opiniones de los filósofos más ilustres, VII, 136, 1. 11061109, p. 553, también en Stoicorum veterum fragmenta, vol. I, n. 102, p. 28, 1. 25-28.

17 Atanasio desarrollará una distinción parecida entre la Sabiduría creadora y la impronta de esta sabiduría en las creaturas, al final del segundo Discurso contra los arrianos, 78-81, pero sin ninguna referencia a la tradición filosófica.

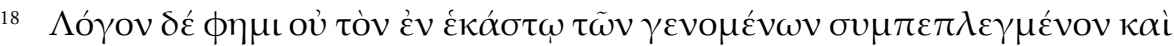

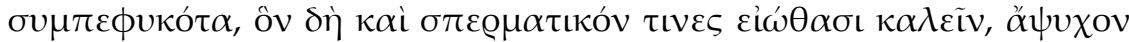

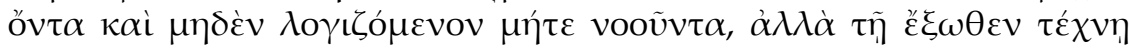

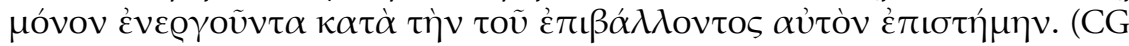
$40,4)$

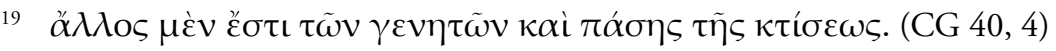


La trascendencia del Verbo de Dios en relación con la creación es la razón teológica que determina la prudencia de Atanasio en esta parte todavía sólo filosófica de su doble tratado apologético. No se puede decir que el Verbo está en el mundo.

Pero sí se puede decir que viene en el mundo. Cito a Atanasio:

El Verbo del Padre, el santo <Verbo $>$ todopoderoso y todo-perfecto, viniendo hacia todas las $\langle$ cosas $>$, extendiendo por todas partes sus potencias, e iluminando todas las < cosas $>$, las visibles como las invisibles, las contiene y las junta, incluyéndolas en él, sin dejar nada vacío de su potencia ${ }^{20}$.

Quisiera destacar esta última palabra: "potencia”. Aunque Atanasio describe la acción del Verbo en el universo como un llenar todo el espacio, lo que llena el espacio no es su presencia, sino su potencia.

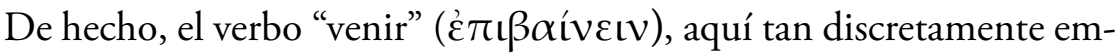
pleado para describir, no la presencia, sino la acción del Verbo en el mun$\mathrm{do}^{21}$, Atanasio lo va a reservar, en la segunda parte de su doble tratado, para describir la venida del Verbo en un cuerpo humano ${ }^{22}$.

\section{SOBRE LA ENCARNACión: La INMANENCIA DEL VERBo EN EL MUNDO}

Leamos ahora las palabras solemnes con las que Atanasio presenta la encarnación del Verbo:

El Verbo de Dios incorpóreo, incorruptible e inmaterial se hace presente en nuestra región, aunque antes, nunca estuviera lejos de ella. De hecho, ninguna parte de la creación se había quedado vacía de él. Al contrario, lo llenaba todo por todas partes, mientras quedaba unido a

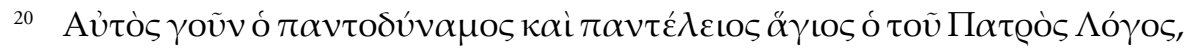

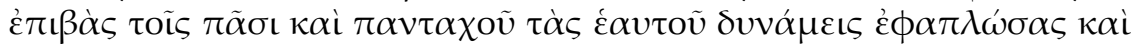

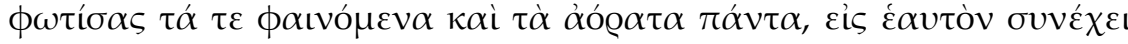

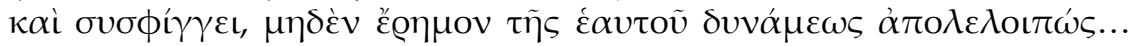
$(41,3)$

21 CG, 41, 2; 42, 1; DI, 41, 5.6.7 y 42, 6 .

22 DI, 9, 1; 20, 4.6; 31, 4; 41, 5; 43, 4. Ver el análisis de Ch. Kannengiesser en SC 199, p. 95: "À une mention près en $I I C A$, l'emploi christologique de ce verbe est une autre particularité du DI..." Habría que leer detenidamente el doble uso de $D I, 41,5$, así como el uso del mismo verbo para hablar de la relación del alma con el cuerpo en CG, 33, 3 . 
su Padre. Pero se hace presente por condescendencia, en virtud de su amor hacia nosotros, los hombres, y de su manifestación ${ }^{23}$.

Con estas palabras retoma Atanasio las reflexiones sobre la acción creadora y ordenadora del Verbo de Dios, que ya hemos leído, y las articula con lo que ahora sí llama presencia del Verbo en el mundo.

Pues, ahora sí, el Verbo, por el cuerpo humano que hace suyo, se puede decir que está en el mundo, lo que, de por sí, implica que está en un determinado lugar del mundo, el que ocupa su cuerpo. Para expresar este punto, Atanasio recurre a la imagen del rey en su reinado, una imagen ya usada varias veces en el Contra los paganos, y que encontramos también en el tratado Acerca del mundo del pseudo-Aristóteles ${ }^{24}$. Este "rey grande", "cuando entra en una ciudad grande", "habita en una sola de las casas que se encuentran en esta <ciudad>”, y no en todas a la vez ${ }^{25}$. El cuerpo-casa, entonces, es el "instrumento" 26 mediante el cual el Verbo puede "entrar" en la ciudad-mundo, y así manifestarse y obrar a través de las condiciones espaciales y temporales propias al mundo.

Sin embargo, la imagen del rey alojado en una determinada casa de la ciudad sirve sobre todo para comprender cómo la presencia localizada en un único lugar no impide, sino que, al contrario, permite, extender su acción sobre todos los lugares. Y esto, gracias a su potencia infinita ${ }^{27}$.

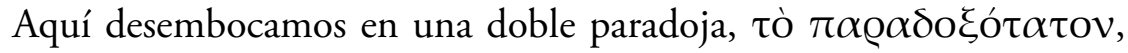
como le gusta decir a Atanasio (DI, 17, 1).

$\mathrm{Al}$ nivel de su acción de creación y ordenación del mundo, el Verbo es, al mismo tiempo, "exterior al universo por el ser, y en todas <las cosas>

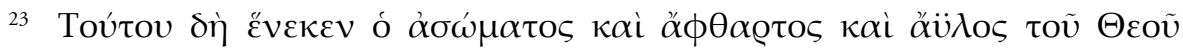

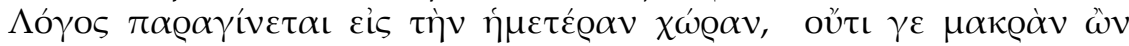

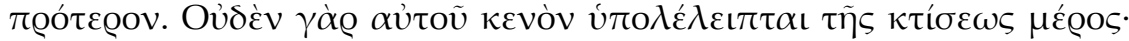

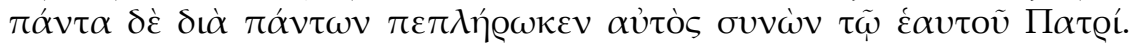

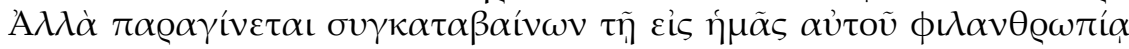

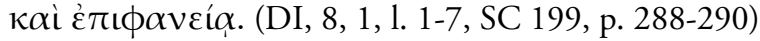

24 Ver Pseudo-Aristóteles, Acerca del mundo, VI, 398a12-b7.

25 DI, 9, 3, 1. 20-22 (SC 199) 296.

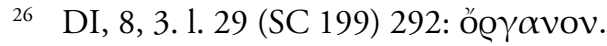

27 Atanasio no siempre se encuentra coherente con sus ejemplos. Retoma la imagen del alojamiento del rey en un sentido contrario en DI, 55, 4: el rey tiene que salir de su casa para manifestarse en una región determinada y restablecer el orden por su "presencia” ( $\pi \alpha \varrho o v \sigma i ́ \alpha)$. 
por sus potencias"28. A este nivel, si está en el mundo, lo está como "conteniéndolo y no como contenido por él” ${ }^{29}$. El único lugar del que se puede hablar para el Verbo, no es propiamente un lugar, sino una persona: El Verbo "está" y "reposa" "sólo en su Padre" 30. Como lo dirá Atanasio en su tratado Acerca de las decisiones de Nicea, "estar en el seno" del Padre no tiene un sentido espacial sino relacional: “¿Qué significa las palabras "en el seno”, sino la auténtica generación del Hijo proviniendo del Padre?”31.

Esta paradoja de un estar-en que es un contener-en-sí, permite de entender mejor la encarnación. La presencia del Verbo en un determinado cuerpo humano no lo "encierra" 32 en él, sino que esta presencia es simultánea a la "acción" 33 del Verbo sobre el universo entero. Esto no se relata sólo al período de su existencia mortal. Desde su resurrección, el Salvador sigue ejerciendo una influencia en los hombres, ahora de manera invisible $^{34}$, de tal modo que, analógicamente, se puede seguir hablando de una "presencia de Cristo" 35 , aunque, como en el caso de la acción creadora del Verbo, se trata, más bien, de una agencia de Cristo, si me permiten este neologismo ${ }^{36}$.

28 DI, 17, 1, 1. 1 (SC 199) 324.

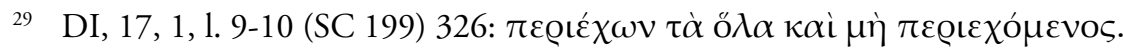

30 DI, 17, 1, 1. 10-11 (SC 199) 326; DI, 17, 4, 1. 27, (SC 199) 328.

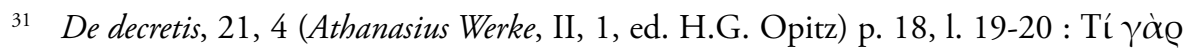

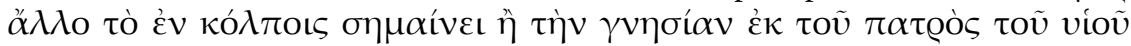
$\gamma \dot{\varepsilon} v \mathrm{v} \eta \sigma \mathrm{ov}$

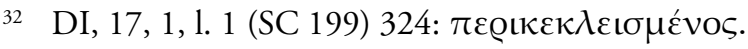

33 DI, 17, 1, 1. 3 (SC 199) 324: غ̇vé $\gamma \varepsilon \varepsilon \alpha$.

34 DI, 30, 4, 1. 25 (SC 199) 374.

35 DI, 31, 2, 1. 13 (SC 199) 376.

36 Podríamos comparar con la distinción escolástica entre estar por esencia, por presencia y por potencia. En su Suma de teología, I, q. 8, a. 3, Tomás de Aquino emplea la analogía del rey: dicitur esse in toto regno suo per suam potentiam, licet non sit ubique praesens. En "La théologie du $\Lambda$ ОГО $\Sigma$ chez saint Athanase (suite)", Revue des Sciences religieuses 11 (1931) 1-26, A.-J. Gaudel ya hablaba de "présence opérative du Verbe dans les choses" (p. 7). El Logos "est hors de tout par sa substance; il est en tout par ses puissances" (p. 8). En un contexto marcado por la doctrina posteriora de las energías divinas, G. Florovsky dice lo mismo en "The Concept of Creation in Saint Athanasius" (Studia Patristica, VI, Oxford, 1962) 36-57: "The Logos is present in the world, but only 'dynamically', that is by His 'powers'. In His own 'substance' He is outside of the world" (p. 46). De hecho, las frases de Gaudel y Florovsky traducen DI, 17, 1, 1. 6-7 (SC 199) 324 y 326. 


\section{Conclusión}

Cuando Santo Tomás de Aquino afirma que "Dios está en todas la cosas", precisa inmediatamente que lo está "como un agente está presente o en lo que actúa" ${ }^{37}$. En este comentario prudente, encontramos, por así decirlo, el legado de la reflexión de Atanasio sobre la presencia de Dios en el mundo. Tomando partido, con el autor del tratado Acerca del mundo, a favor de la trascendencia del Dios creador, el obispo de Alejandría reserva el concepto de "presencia" a la encarnación del Verbo. En cambio, la relación entre el Verbo y el mundo no puede expresarse al nivel del "estar", sino del "hacer", o mediante una paradoja: el Verbo contiene en sí lo que llena de sí.

Esta paradoja, si tuviéramos más tiempo, tendríamos que compararla con las reflexiones de un Platón o de un Plotino sobre el alma universal, que el creador "extendió a través de" todo el cuerpo del mundo, "e incluso afuera de él, para envolver el mundo con ella a su alrededor ${ }^{38 ”}$.

De hecho, Atanasio menciona la idea atribuida a "filósofos griegos" de que "el Verbo de Dios esté en el mundo en cuanto <el mundo> es un cuerpo" (DI, 41, 5), pero no compara explícitamente el Verbo con el alma ${ }^{39}$. Sin embargo, cuando habla de la relación entre el alma y el cuerpo, usa

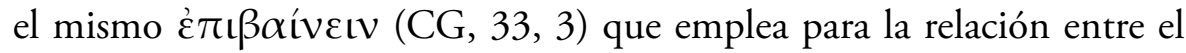
Verbo y el mundo.

Aquí tenemos, pues, otro ejemplo de cómo el anuncio de la venida del Verbo en la economía de la carne dialoga críticamente con los discursos filosóficos sobre Dios, para aproximarse al que tiene un "nombre incomunicable" (Sb 14, 21, citado en CG, 11, 1; 17, 3).

El profundo anhelo del ser humano es conocer a su principio. En las condiciones que rigen nuestra existencia en el mundo, siempre conocemos una cosa mediante un acercarse a la cosa para que se presente a noso-

37 Suma de teología, I, q. 8, a. 1: Deus est in omnibus rebus [...] sicut agens adest ei in quod agit.

38 Platón, Timeo, 34b.

39 En este sentido, habría que matizar la interpretación de A. Grillmeier, Cristo en la tradición cristiana, I, Desde el tiempo apostólico hasta el Concilio de Calcedonia (451) (trad. esp., Salamanca, 1997) 507, cuando dice que Atanasio "colocó en cierto modo al Logos concebido personalmente -a diferencia del estoicismo- en el puesto del 'alma'”. 
tros. Pero, con Dios, no es así. Atanasio, distinguiendo claramente entre la naturaleza divina y la naturaleza humana del Verbo encarnado, destaca cómo el Salvador de los hombres, en cuanto hecho hombre, es conocido "mediante su presencia corporal" 40 , mientras que es conocido como Hijo de Dio sólo "mediante las obras de la creación” ${ }^{2}$. Aquí tenemos apuntes para una teología fundamental que sepa renunciar definitivamente a un Dios presente, un Dios que está aquí, a favor de un Dios agente, un Dios que actúa sobre el aquí.

Empecé esta reflexión hablando de criterios para demostrar la verdad de un determinado dios. Creo que lo que hemos aprendido de Atanasio, y, más globalmente, de la tradición teológica cristiana, concuerda con las intuiciones bíblicas. La verdad de Dios no es su presencia, sino su potencia o, si me permiten, su agencia.

Dios nos toca, no porque estaría presente en el mundo, rodeándonos como nos rodeaba, protectora, la matriz materna en los primeros meses de nuestra vida, sino porque actúa sobre el mundo. Sí, Dios nos toca. Tocar es un modo paradójico de relacionarse con alguien, puesto que tocar es, a la vez, rozar ligeramente, superficialmente, y emocionar hasta las entrañas. Decir que Dios nos toca, es decir que tiene con nosotros una relación paradójica. Esto podría sonar, al final de esta reflexión, como un rechazo definitivo, por parte de la teología, del pensamiento racional y de la tradición filosófica que lo promueve. Pero una de las grandes tareas del pensamiento racional es, precisamente, pensar lo paradójico. En esta medida, el pensamiento racional es imprescindible para la teología, y el diálogo con la tradición filosófica, siguiendo las huellas de los Padres de la Iglesia, es una de sus tareas esenciales.

40 DI, 18, 2, 1. 11 (SC 199) 330: $\sigma \omega \mu \alpha \tau \iota \kappa \tilde{\omega} \varsigma \pi \alpha \varrho \omega ́ v$.

41 DI, 18, 3, 1. 17-18 (SC 199) 330. 